

\title{
Determination of Total Gas in Lithium Tritide-Deuteride Compounds
}

\author{
Maynard E. Smith \\ Nancy L. Koski \\ Glenn R. Waterbury
}

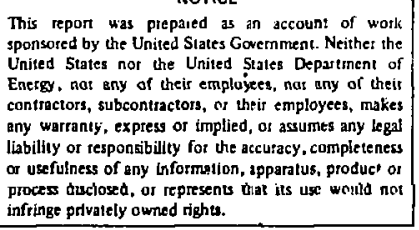




\title{
DETERMINATION OF TOTAL GAS IN LITHIUM TRITIDE-DEUTERIDE COMPOUNDS
}

\author{
by \\ Maynard E. Smith, Nancy L. Koski, and Glenn R. Waterbury
}

\begin{abstract}
Lithium tritide-deuteride sampies are enclosea in a copper foil and decomposed by heating to $850^{\circ} \mathrm{C}$ in a copper reaction tube in vacuum. The temperature and pressure of the evolved gas, collected in a measured volume using a Toepler pump, are measured to determine the total nioles of gas released from the sample. The gas is transferred to a removable sample bulb and, if required, analyzed for gaseous constituents by mass spectrometry. Based on 14 total gas determinations for a lithium deuteride sample, the calculated relative standard deviation was $1.0 \%$ and the estimated bias was $<2.5 \%$.
\end{abstract}

\section{INTRODUCTION}

The use of lithium tritide-deuteride as a thermonuclear fuel in laser fusion experiments necessitated the development of a method for determining the total gas in this material. If required, a sample of this gas may be used for mass spectrometric determination of its composition. Because many materials, such as stainless steel and quartz, evolve hydrogen when heated, a reaction tube that will minimize this effect is required. Copper, demonstrated to be satisfactory in this application, was used for both the sample container and reaction tube.

\section{APPARATUS AND REAGENTS}

\section{Apparatus}

Balance, capable of weighing up to $0.1 \mathrm{mg}$ in an inert atmosphere enclosure.

Foil, 0.025-mm (0.001-in.)-thick.

Foil holder, solid support with hole for holding cylindrical copper foils upright during filling operation.

Forcep8, dissecting, 115-mm-long; one straight and one curved.

Inert atmosphere enclosure, containing argon gas with a <5-ppm moisture and os vgen content; modified for preparation of tritium-containing samples (see Sampie Preparation section below). 
Pres8ure regulator, one, low-pressure, capable of regulation at 2.5 to $3.7 \mathrm{kPa}(10-15 \mathrm{in}$. of water); and one, capable of regulation at $103 \mathrm{kPa}$ (15 psi).

Spatula, vibrating type preferred for loading copper foils.

Total gas analysis apparatus, consisting of the following items, assembled as shown in Fig. 1. Deaiccant tube, borosilicate glass, filled with anhydrous magnesium perchlorate and plugged with glass wool at each end to contain reagent dust.

Furnace, resistance, for heating 9.5-mm (0.375-in.) copper tube to $850^{\circ} \mathrm{C}$.

Laboratory jack, for adjusting furnace height.

Magnet, for operating sample d'umper.

Mercury diffusion pump, pumping speed $\sim 120 \mathrm{l} / \mathrm{s}$ or faster.

Mercury reservoir

Micromanometer, with sensor head that can be used with tritium (MKS single-sided head or equivalent).

Reaction tube, made from hard-drawn copper tubing, 9.5-mm (0.375-in.)-o.d., 1.65-mm (0.065-in.) wall thickness, and 203-mm (8-in.)-long, sealed at one end by flowing helium through the tube while heating the end in a gas-oxygen flame and striking with a hammer. A copper coupling is hard soldered to the other end and the ridge left by the inserted tube is beveled using a $9.5-\mathrm{mm}(0.375$-in.) counter sink. The other end of the coupling is hard soldered to a Kovar metai-glass seal connected to a 14/35 standard-taper borosilicate glass outer joint.

Sample bulbs, 25-m $\ell$, equipped with pressure stopcock.

Sample dumper

Solenoid valves, two, 6-W, 115/230-V, 172-kPa (25-psi), 6.35-mm (0.25-in.) pipe, 5.55-mm (0.218-in.) orifice for activating Toepler pump.

Stopcocks, five, straight-bore, 4-mm; two, oblique-bore, 4-mm; and two, oblique-bore, 3-way, 4-mm.

Thermocouple gauges, two, 0- to 133-Pa (1-torr).

Thermometer, digital or otherwise, readable to $0.1^{\circ} \mathrm{C}$.

Timers, two, electric, $30-\mathrm{s}$, wired to solenoid valves so that one controls the vacuum half of the Toepler pump cycle and the other controls the pressure half of the cycle.

Toepler pump, 250-m $\ell$, with 4-mm, straight-bore, stopcock inserted between bulbs.

Tubing, stainless steel, 19-mm (0.75-in.)-o.d.

Valves, three, stainless-steel, bellows, with $19-\mathrm{mm}(0.75$-in.) tube connections, and two metering valves, with $6.35-\mathrm{mm}(0.25$-in.) tube connections.

\section{Rergents}

Argon, tank.

Desiccant, magnesium perchlorate, anhydrous.

Grease, silicone.

Mercury, distilled.

\section{Caution}

Any work that involves the handling of tritium-containing materials should be done only under approved safe conditions and in laboratories designed for adequate protection of the workers. Rules recommended for the safe handling of such materials should be rigidly followed. 


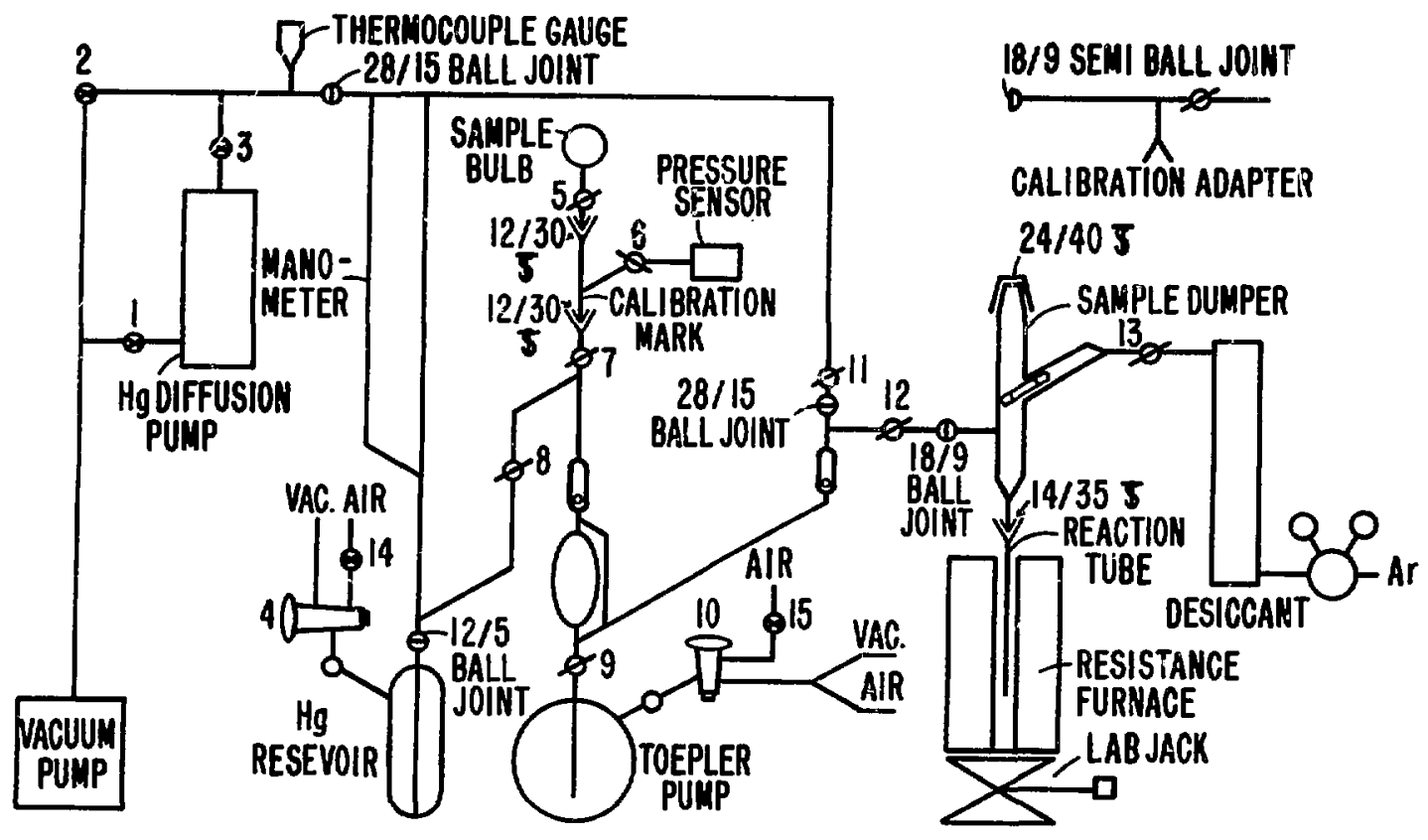

Fig. 1.

Apparatus for determination of total gas in lithium tritide-deuteride samples.

\section{SAMPLE PREPARATION}

Samples of alkali hydrides, deuterides, and tritides must be prepared in a dry inert enclosure because of their reaction with moisture. Inert enclosures for handling tritides must be modified to prevent release of tritium into the atmosphere. Gases escaping from these enclosures are passed over copper oxide heated to $650^{\circ} \mathrm{C}$ to convert the tritium to water, which is trapped in a molecular sieve in a stainless steel tube. This unit is eventually removed from the system and sent to a tritium recovery facility. Samples weighing no more than $7 \mathrm{mg}$ are obtained and weighed $\left(W_{1}\right)$ to the nearest $0.1 \mathrm{mg}$ as follows: (1) a tube made from copper foil is sealed (folded) at one end and weighed, (2) the sample is placed in the tube using a vibrating microspatula, and (3) the foil is sealed by folding over the end, and then the foil and the sample are reweighed $\left(\mathrm{W}_{2}\right)$.

The sample weight may then be obtained by the difference between $W_{2}$ and $W_{2}$. The foil containing the sample is placed in a vial with a tightly sealing screw cap and transferred to the analysis apparatus just before analysis.

\section{RECOMMENDED PROCEDURE}

1. Turn on both vacuum pumps, turn on air supply valve, adjust pressure to $103 \mathrm{kPa}$ (15 psi), turn on argon flow, and adjust pressure to $147 \mathrm{~Pa}$ (15 in. of water).

2. Connect copper reaction tube to sample dumper, open stopcock 9 , then open stopcocks 4 and 10 to the vacuum side. Close stopcricks 4 and 10 when mercury has completely drained into reservoirs.

3. Close stopcocks 9 and 13 (leave stopcocks 4 and 10 closed), but open all other stopcocks and valves 1,2 , and 3 . 
4. When thermocouple reads $<1.3 \mathrm{~Pa}(10 \mu)$ of pressure, close valve 2 and turn on cooling water and diffusion pump. Turn on micromanometer and bake sensor head for about $1 \mathrm{~h}$. Switch to regulate and allow to stabilize overnight.

5. Evacuate system to $<0.6 \mathrm{~Pa}(5 \mu)$ of pressure and test for leaks by temporarily closing valve 3 and watching for a rapid rise in pressure, as shown by thermocouple gauge, that would indicate a leak.

6. When system is satisfactorily evacuated, raise resistance furnace so that reaction tube is in position and heat tube to $850^{\circ} \mathrm{C}$ for at least $1 \mathrm{~h}$.

7. Zero micromanometer and close stopcock 6.

8. Turn stopcock 4 to admit compressed air into mercury reservoir; with metering valve 14 , adjust mercury column to just below entrance of side arm into Toepler pump; close stopcock 8.

9. Close valve 14 and stopcocks 4 and 11 , open stopcock 9 , and open stopcock 10 to Toepler pump control.

10. Activate Toepler pump; after 10 strokes, raise mercury level to side arm of mercury reservoir. (This is done most readily by moving back timer hand of pressure control and adjusting level with stopcock 9 , which should be closed after adjustment is made.)

11. Turn off Toepler pump control and open stopcock 6 .

12. Open stopcock 4 to compressed air, open stopcock 8 , use metering valve 14 to adjust column of mercury to calibration mark below stopcock 6 , and close stopcock 4 . If pressure on micromanomater is $<40 \mathrm{~Pa}(0.3$ torr), apparatus background is satisfactory.

13. If micromanometer pressure is $>40 \mathrm{~Pa}$, drain mercury into reservoir (see Step 2) and repeat steps 5 through 12 . If a satisfactory value is not obtained, install a new reaction tube (see steps 31 thirough 34 ).

14. When apparatus background is satisfactory, close stopcocks 8 and 6 , and open stopcock 11 .

15. Close stopcock 12 and open stopcock 13.

16. Ascertain that sliding rod inside sample dumper is in pesition to prevent sample from dropping into reaction tube, remove cap, and drop sample into dumper taking care to prevent exposure of sample to air.

17. Replace cap loosely, allow systen to flush for a few seconds, seal cap, and attach holding spring.

18. Close stopcock 13 and valves 15,1 , and 3 ; open valve 2 , then open stopcock 12 .

19. When thermocouple gauge indicates $<1.3 \mathrm{~Pa}(10 \mu)$ of pressure, close valve 2 and open valves 1 and 3.

20. Drain mercury into reservoir by opening stopcock 8 and stopcock 4 to vacuum side, anci iv.ser mercury in 'Toepler pump by opening stopcock 10 to Toepler pump control and then opening stopcock 9.

21. Open stopcock 6, and evacuate system for 5 to $10 \mathrm{~min}$.

22. Proceed according to steps 7 through 9 but raise mercury about halfway up manometer arm (step 8) to accommodate pressure released from sample.

23. Use a magnet to activate sample dumper and drop sample into reaction tube.

24. Proceed according to steps 10 through 12 , then measure pressure with micromanometer; record pressure and temperature of sample bulb.

25. Close stopcock 6 , use metering valve 14 to raise mercury up to stopcock 5 on sample bulb.

26. Close stopcocks 5 and 8 , turn stopcock 4 to vacuum side, and lower mercury using stopcock 8 to a position just below standard-taper joint connecting sample bulb.

27. Close stopcccks 8 and 7 , then remove sample bulb and set it aside for mass spectrometric analysis.

28. Connect another sample bulb (previously evacuated) to apparatus and close stopcock 12 .

29. Pressurize reaction tube using stopcock 13 , lower resistance furnace, and remove reaction tube. 
30. Connect a new reaction tube to apparatus, close valves 1 and 3 , and open valve 2 .

31. Ascertain that stopcock 13 is closed, then open stopcocks 11 and 12.

32. Drain mercury into reservoir by opening stopcocks 7 and 8 .

33. When thermocouple gauge registers $1.3 \mathrm{~Pa}(10 \mu)$ of pressure, close valve 2 and open valves 1 and 3.

34. Drain mercury into Toepler pump reservoir by opening stopcock 9 . If more analyses are required, open stopcocks 5 and 6 , and begin analysis procedure starting with step 6; otherwise, place apparatus on standby by closing stopcocks $4,6,9$, and 10 . For complete shutdown, (1) also close vaives 1,2 , and $3,(2)$ turn off compressed air and argon, (3) turn off and vent both vacuum pumps, and (4) turn off diffusion pump heater and, when cool, shut off cooling water.

\section{CALCULATIONS}

Use the following formula to calculate the micromoles per milligram.

$$
\begin{aligned}
\mu \mathrm{mol} / \mathrm{mg} & =\frac{2.135 \times \text { pressure }(\mathrm{kPa}) \times \text { calibrated volume }(\mathrm{ml})}{\text { temperature }(\mathrm{K}) \times \text { sample weight }(\mathrm{mg})} \\
\mathrm{kPa} & =7.50 \times \text { pressure }(\text { tors })
\end{aligned}
$$

\section{CALIBRATION}

Calibration volume must be determined as follows for each sample bulb used. This volume includes not only the bulb volume but the volume of the apparatus above the calibration mark including the pressure sensor volume.

1. Calibrate a 5- and 6-m $\ell$ bulb, equipped with a stopcock and standard-taper joint, by weighing bulb when firied with water and when evacuated. To calculate bulb volume, divide the difference between the two weights by the water density at ambient temperature. (The total bulb volume should include the stopcock bore.)

2. With stopcock 12 closed, replace the sample dumping section with the calibration adapter (see Fig. 1), which permits a calibrated bulb to be connected to the apparatus.

3. Open bulb to the atmosphere, then ciose stopcock after recording barometric pressure and temperature.

4. Connect bulb to the calibration adapter leaving the stopcock closed and follow steps 1 through 12 (omitting step 6) of the Recommended Procedure. Note that the closed calibration bulb has been substituted for the copper reaction tube.

5. If the apparatus background pressure is $<40 \mathrm{~Pa}(0.3$ torr $)$, open stopcock 11 and proceed according to steps 21 and 22 of the Recommended Procedure.

6. Open calibration bulb stopcock and proceed according to steps 10 and 11 of the Recommended Procedure.

7. Record pressure reading indicated by micromanometer and temperature of the sample bulb, then proceed according to step 34 of the Recommended Procedure.

8. Calculate calibration volume of the sample bulb by the following formula 


$$
V_{1}=\frac{B \times V_{2} \times T_{1}}{P \times T_{2}}
$$

where

$$
\begin{aligned}
& \mathrm{V}_{1}=\text { calibration volume in } \mathrm{m \ell} \\
& \mathrm{B}=\text { barometric pressure in } \mathrm{kPa} \\
& \mathrm{V}_{2}=\text { calibration bulb volume in } \mathrm{m \ell} \\
& \mathrm{T}_{1}=\text { temperature of sample bulb in } \mathrm{K} \\
& \mathrm{P}=\text { micromanometer pressure in } \mathrm{kPa} \\
& \mathrm{T}_{2}=\text { calibration bulb temperature in } \mathrm{K} \\
& \mathrm{kPa}=7.50 \times \text { pressure (torr) }
\end{aligned}
$$

\section{EXPERIMENTAL}

The value obtained for 14 determinations of total gas in a lithium deuteride sample was 54.48 $\mu \mathrm{mol} / \mathrm{mg}$, which represents a $97.6 \%$ recovery based on the theoretical value for li', hium deuteride. The relative standard deviation was $1.0 \%$. Upon receiving the sample, an attempt was made to prevent its contact with moisture by storing it in an inert gas enclosure, ${ }^{1}$ because the material is highly reactive and combines with water according to $\mathrm{LiD}+\mathrm{H}_{2} \mathrm{O}=\mathrm{LiOH}+\mathrm{HD}$. This results in a decrease in the total gas per unit weight of material. Because the exact history of the material is not known and a reliable assay of the material was not available, the purity of the compound was uncertain. Unfortunately, no other standard material was available.

\section{CONCLUSIONS}

The method described in this report may be used for the determination of the total quantity of hydrogen isotopes (protium, deuterium, and tritium) in lithium compounds that may be decomposed completely at $850^{\circ} \mathrm{C}$ or less. It also should be applicable to those samples that decompose in this temperature range and produce noncondensable gases. Semples that release gases that are condensable or corrosive to mercury cannot be analyzed with this method. Although a suitable standard was not available, the data indicate that the bias is $<2.5 \%$. A relative standard deviation of $1.0 \%$ was calculated based on 14 determinations of lithium deut ride.

\section{ACKNOWLEDGMENTS}

We are grateful to James Anderson, Joseph Nasise, and coworkers in CMB-3 for supplying the samples used in testing the method and for their helpful suggestions and information.

\section{REFERENCE}

1. M. E. Smith, J. M. Hansel, and G. R. Waterbury, "An Inert Atmosphere Enclosure for the Preparation of Samples Prior to the Determination of Oxygen," Los Alamos Scientific Laboratory report LA-3344 (August 1965). 